\title{
Traditional Aipan Art of Kumoun - A Sustainable Development Tool
}

\author{
Manisha Gahlot, Pooja Bhatt*, Deepti Pargai and Beenu Singh \\ Department of Clothing and Textiles, College of Home Science, G.B. Pant University of \\ Agriculture and Technology, Pantnagar, U.S. Nagar, Uttarakhand, India \\ *Corresponding author
}

\section{A B S T R A C T}

\section{Keywords}

Apian, Kumaon, Cultural heritage,

Folk art,

Sustainable

\section{Article Info}

Accepted:

25 September 2020

Available Online:

10 October 2020
India is a land of rich cultural heritage, which is enriched by countless forms of folk arts as well. These folk art forms are an embodiment of the diverse cultures within the country and each one is different and unique from the rest. Every Indian state has its own folk art form, in the Kumaon region of Uttarkahnd Aipan is one of the traditional art (painting form) which has great social, cultural and religious significance. The economic impact of the 2020 Corona virus pandemic in India has been largely disruptive. India's growth in the fourth quarter of the fiscal year 2020 went down to $3.1 \%$ according to the Ministry of Statistics. Covid crisis has shown that there are many ways in which some degree of selfreliance should be supported and expanded. Aipan folk is one of such kind, which has the potential of successfully engaging the migrants. In the present study existing traditional designs of Aipan were collected and then adapted using corel draw for printing techniques and embroidery stitches so as to use them in different arrangements on articles like bags, cushion covers, stoles and shrugs. The prepared adapted designs were evaluated by judges, to find out the suitability of the developed designs for printing techniques and embroidery stitches. The blend of Aipan design with printing provided an imaginative and modern collection to the people who want to retain their tradition with minute modernization.

\section{Introduction}

Due the wide spread pandemic people are coming back to their native places, so flow of migrant workers is increasing and it will continue to grow. The situation has raised a challenge of engaging them in local and gainful employment. This situation can only be tackled by skill development as it enhances both people's capacities to work and their opportunities at work. Development of skills among the migrants is the most important responsibility of the government and society as well and should be dealt very carefully. It is a well known fact that hand-picked, handmade, local, ethnic, green, organic and natural products are better than the factory-made, the chemical and the formula-run have been around for a while.

This is the high time to revive Aipan craft of Uttarakhand. Most of the people of Kumaun are aware of the Aipan craft so it is straightforward for them to take it in the form of income generating activity. This will produce welfare, sustainable income, help in 
job creation and all in all, put faith in the people. The main aim of the study was to revitalize and explore the folk art of "Aipan" as a source of income generation for people of Uttarakhand.

The folk art, Aipan is practiced among people of kumoan region in Uttarakhand state at the places of worship, houses. Aipan has religious and cultural significance (Bhandari 2006). This folk is having are geometric designs made on red background of geru with rice paste (white). The main symbols used in this are the dot, triangle, circle, square, swastika and lotus and their various combinations. There are specific Aipans for almost all religious occasions (Arya et al., 2017).

Basically two forms of Aipan namely ritualistic and the decorative form is prevalent. The ritualistic designs usually comprise of a yantra or a symbol assigned to a particular deity, which the artist is required to portray in its assigned shape and place, without any change. These type of designs are made on the floor of the prayer room and serve as a seat or pitha to the deity. In the decorative design drawn around the ritualistic diagrams, the motifs used are often predetermined by the use of auspicious symbols such as shankha, betel and lotus leaves, fish, various creepers and so on. The central part of the Aipan is considered ceremonial and has a prescribed motif while the outer part is decorative and can be extended or reduced to fit an important element without which the Aipan is considered unfinished. (Upadhayay, 2013)

Presently Aipan have been extended its reach and now being painted on greeting cards, wall hangings and other products but Aipan has the great potential of becoming popular as new textile like the other traditional hand printing of Madhubani and Kalamkari.
Due to the modernization, migration of people from their native places and increase in nuclear family system people are not following their traditions. So this traditional art is facing challenges and losing its significance continuously (Traditional Aipan). Presently, the local population of Kumaun is not much aware about significance of the Aipan. Extinction of this art could be prevent by creating awareness among the youngster (Anonymous, 2016). They are using Aipan in modified way like stickers and paint in place of biwsar and geru. Various non-government organizations and government organization are working on conservation of this art. Present study was also an attempt in this direction where the designs were developed for different products through adaptation of Aipan designs. It creates a new definition for the value addition of Aipan and provides new range of designs for different apparel and household products.

\section{Materials and Methods}

Survey was conducted in six districts of Kumaon four districts namely Almora, Nainital, Udham Singh Nagar and Pithoragarh to collect the traditional designs of Aipan from primary and secondary sources as well to know the status of Aipan among the Kumaoni families. From these original Aipan designs motifs were selected and adapted according to the product.

\section{Development of designs}

Aipan designs were adapted designs were adapted to suit the technique of application and developed for block printing, screen printing, sublimation printing (heat transfer) and embroidery stitches without changing the originality of basic designs. The designs were developed using corel draw 7. The designs were made under four categories for each technique i.e. six for screen printing, four for 
block printing, two for heat transfer printing and four for embroidery. Various product range such as cushion cover, shrug, stole and bags of adapted Aipan motifs were prepared using these above mentioned techniques.

\section{Printing and embroidery}

Before printing the fabric was washed to remove the starch. Required amount of paste was spread on felt which was placed over the tray. Block printing was carried out using blocks of Aipan motifs whereas screen printing was done using photochemical screens and squeeze.

Screens and blocks were placed on the fabric as per planned arrangement. After printing the fabrics curing was done using electric iron.

Printing was carried out in heat transfer printing machine using sublimation method. . Machine was kept on $220^{\circ} \mathrm{C}$ for 24 seconds. It transferred sublimation ink on the fabric through high temperature and pressure.

Combination of different stitches namely chain stitch, satin stitch, running stitch, spider web stitch, herring bone stitch, button hole stitch, couching stitch and rose stitch were used in a planned arrangement.

\section{Construction of products}

The printed and embroidered fabrics were constructed and finished into cushion covers, bags, shrug, clutch and stoles. All seams were finished properly. List of products with technique used are given in the Table

\section{Cost calculation of developed product}

Cost of finished products was calculated on the basis of cost of raw material, printing, embroidery and stitching. Other than these, miscellaneous charges $(20 \%)$ and profit (30\%) were also added in the cost.

\section{Evaluation of developed products}

The planned products namely cushion covers, bags, clutch, shrug and stoles were made from printed and embroidered fabrics. The finished products were evaluated by 50 respondents. Respondents consisted of faculty members, Senior Research fellows, Ph.D \& M.Sc. Research Fellows and final year students of Department of Clothing and Textiles and Family Resource Management, College of Home Science GBPUA\&T, Pantnagar.

The products were evaluated to study the acceptability of the developed products. The evaluation of products was done on novelty of design, suitability and arrangement of the motifs or designs on the products, clarity of printing and their overall appearance. Different products were rated using five point rating scale. Weighted mean score was calculated for each criteria.

\section{Statistical analysis}

Collected data was tabulated analyzed according to the study. The statistical measures used for analysis were frequency, percentage, rank and weighted mean score was calculated for each criteria/property.

\section{Results and Discussion}

Different Aipan based products such as cushion cover, shrug, stole and bags were developed using different embroidery and printing techniques. Aipan based developed products are shown in Plate 1 to Plate 4. Evaluation of developed products were done on the basis of different criteria such as Novelty of design, suitability of motifs on products arrangements of motifs color combination, quality of printing/ embroidery and overall appearance. Cost of the developed products was also evaluated. 


\section{Evaluation of developed products}

Table 1 reveals that bag 1 had highest WMS (4.98) for novelty in designs it was followed by cushion 2 and 3 with 4.80 and 4.66 WMS respectively. Shrug with 3.66 WMS was rated lowest by the respondents. In case of stoles, stole 1 was preferred over stole2. Although stole 2 was more colorful then stole 1 respondents found newness in the motifs of stole 1 . There was not much difference in the WMS of bag 3 and bag 4, recorded WMS was 4.22 and 4.28 and ranked $\mathrm{V}$ and VI respectively.

When suitability of motifs was assessed for the developed products it was observed that cushion 1has highest WMS (4.88) and ranked I. On the basis of respondent's choice cushion 2 and bag 1 was ranked II with 7.72 WMS value. Clutch was ranked III (4.30 WMS) and shrug was ranked IV (4.14). Stole 1 got lowest rank (XI) with 3.24 WMS.

Bag 1 was preferred by the most of the respondents, it was ranked I for motif arrangement followed by cushion 2 and shrug. Cushion cover 2 and shrug had 4.64 and 4.52 WMS respectively. Bag was ranked IV with 4.50 WMS. Cushion cover 5 and clutch got V rank with WMS of 4.38. Motif arrangement of bag was least preferred by the respondents, calculated WMS was 3.02.

Table.1 Developed products with technique used for designing

\begin{tabular}{|r|l|c|c|}
\hline S. No. & Products & Number of product & Technique used \\
\hline $\mathbf{1 .}$ & Stole & 2 & Block printing \\
\hline $\mathbf{2 .}$ & Cushion Covers & 5 & Screen printing \\
\hline $\mathbf{3 .}$ & Shrug & 1 & Heat Transfer Printing \\
\hline $\mathbf{4 .}$ & bag & 1 & Heat Transfer Printing \\
\hline $\mathbf{5 .}$ & Bags & 4 & Embroidery \\
\hline
\end{tabular}

Table.2 Preferences of judges for the cost of the products

\begin{tabular}{|r|l|l|l|l|}
\hline \multicolumn{5}{|l|}{ Frequency (Percent) } \\
\hline S. No. & Name of Products & High & Medium & Low \\
\hline 1. & Cushion & $2(4)$ & $42(84)$ & $6(12)$ \\
\hline 2. & Bag 1 & - & $46(92)$ & $4(8)$ \\
\hline 3. & Bag 2 & $38(76)$ & $12(24)$ & - \\
\hline 4. & Bag 3 & $12(24)$ & $35(70)$ & $3(6)$ \\
\hline $\mathbf{5 .}$ & Bag 4 & $3(6)$ & $29(58)$ & $18(36)$ \\
\hline 6. & Stole 1 & $14(28)$ & $36(72)$ & - \\
\hline 7. & Stole 2 & $19(38)$ & $31(62)$ & - \\
\hline 8. & Clutch & $3(6)$ & $41(82)$ & $6(12)$ \\
\hline 9. & Shrug & $46(92)$ & $4(8)$ & \\
\hline & & & & \\
\hline
\end{tabular}


Fig.1 Overall WMS Of different Aipan based products

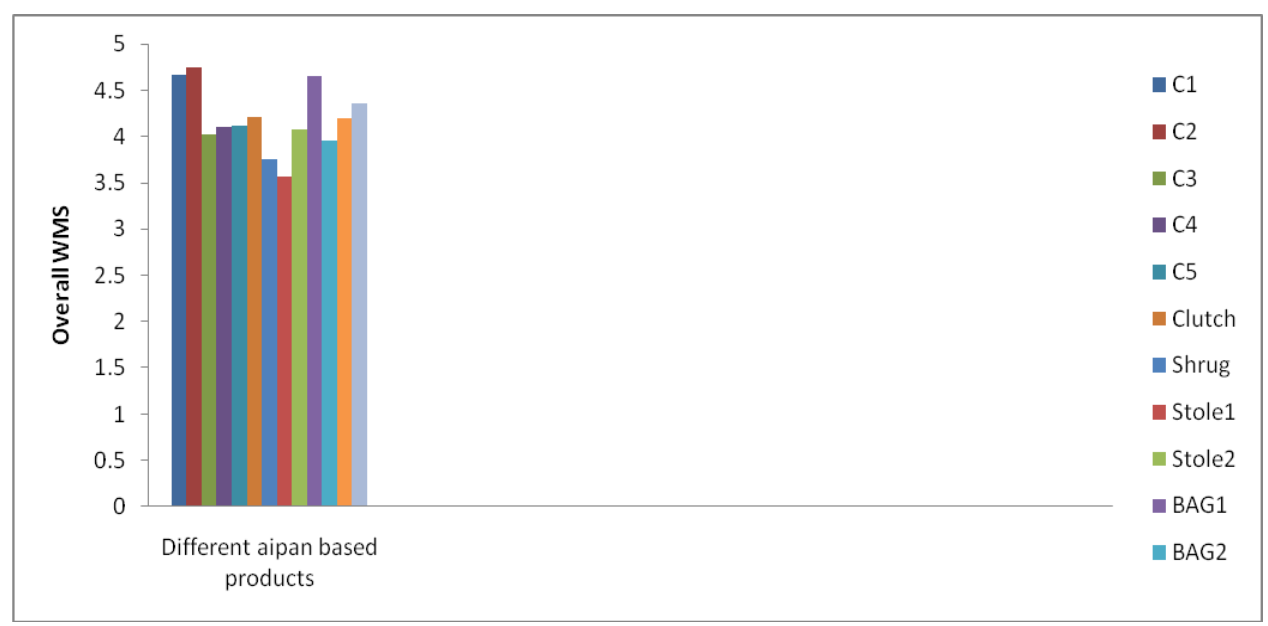

Plate.1 Cushion covers (Technique used: Screen Printing)

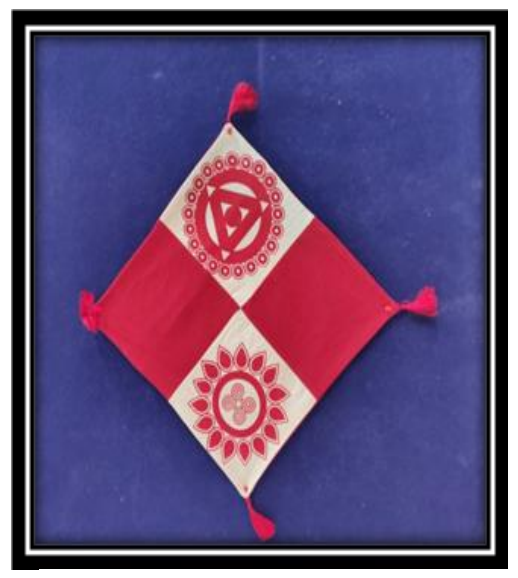

Cushion Cover 1

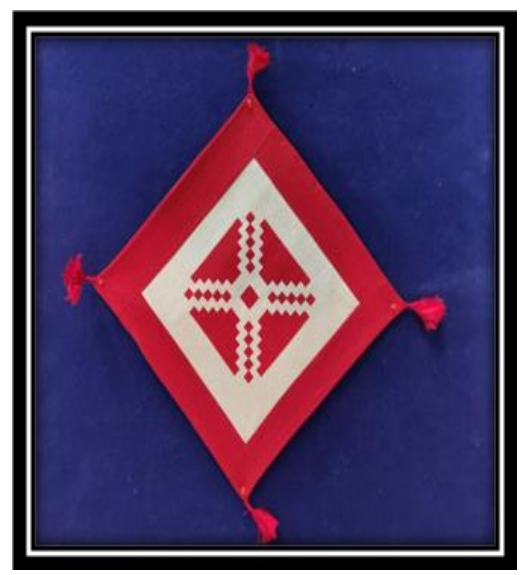

Cushion Cover 2

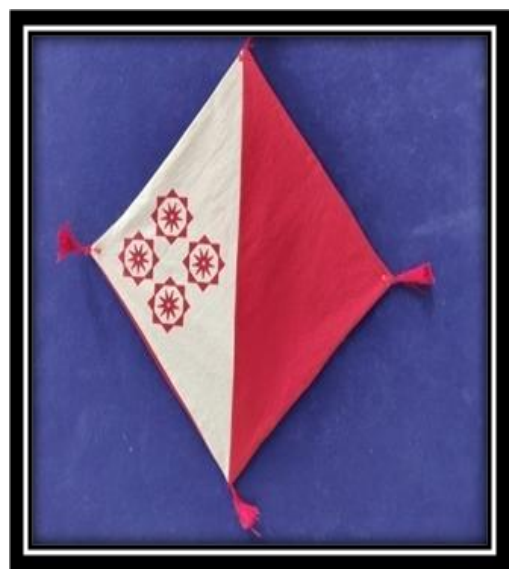

Cushion Cover 3

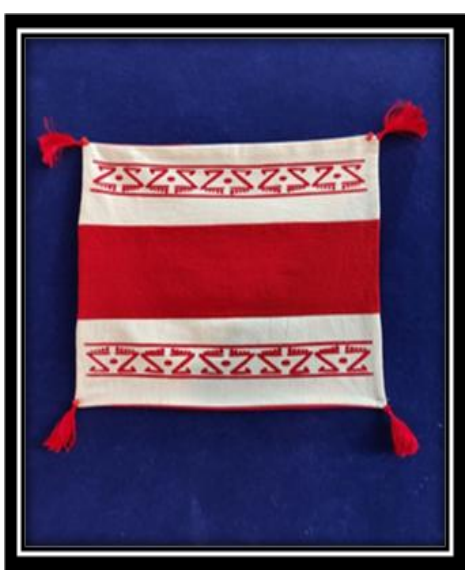

Cushion Cover 4

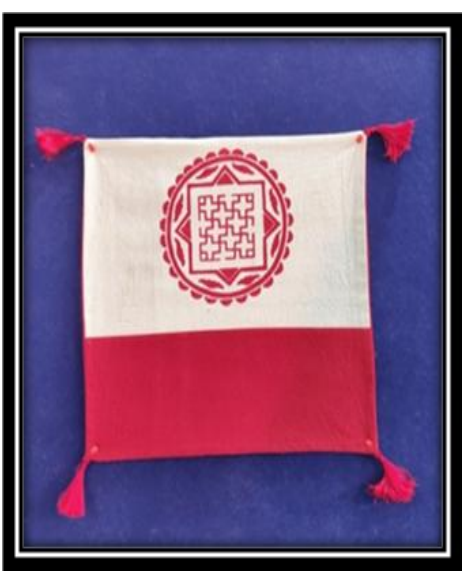

Cushion Cover 5 
Plate.2 Stoles (Technique used: Block Printing)

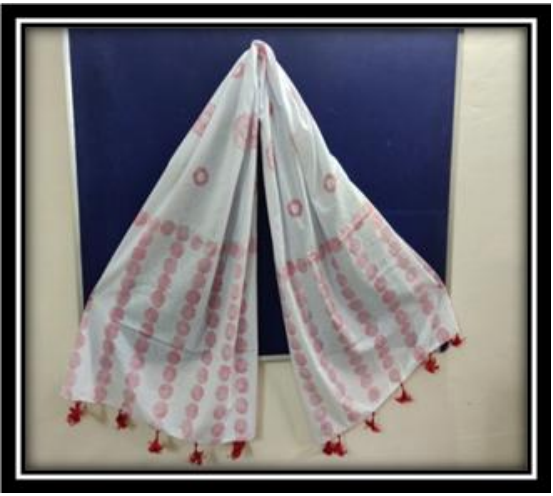

Stole 1

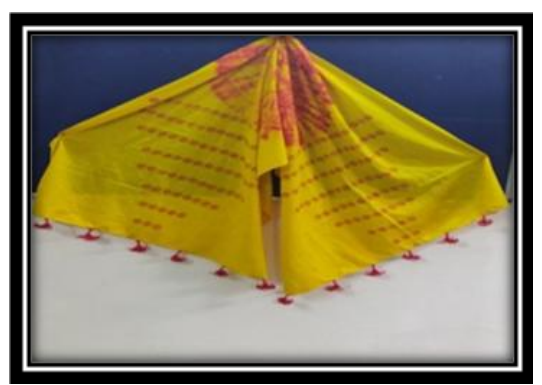

Stole 2

Plate.3 Shoulder bag and shrug (Technique Used: Heat Transfer Printing

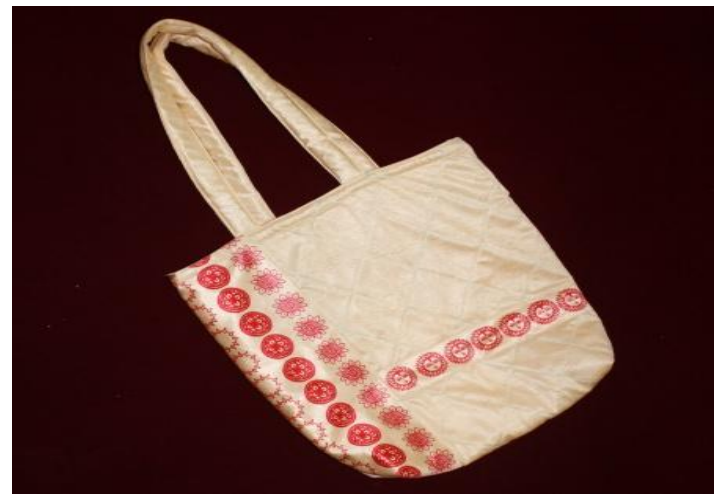

Bag 2

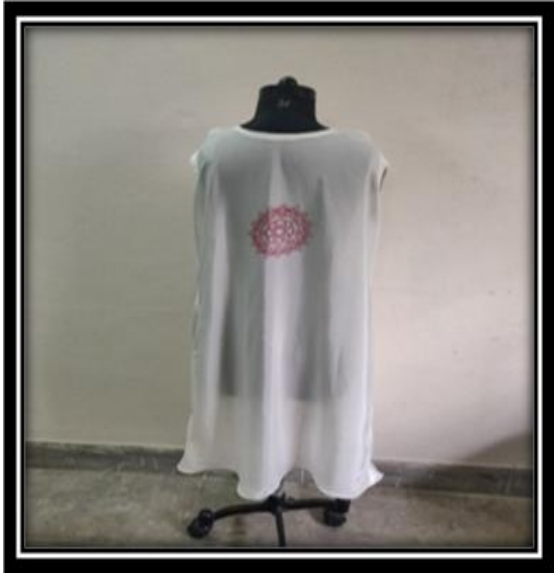

Shrug (Front )

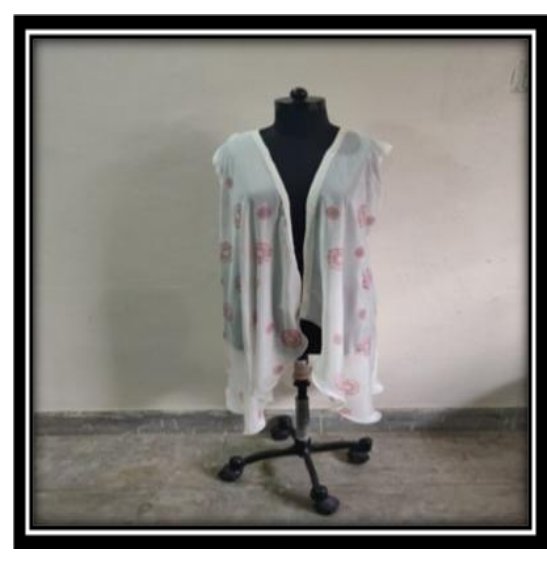

Shrug (Back) 


\section{Plate.4 Bags (Technique used: Embroidery)}

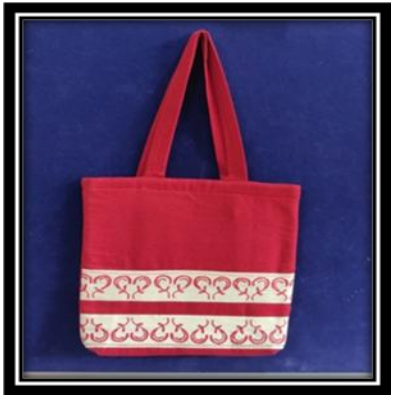

Bag 1

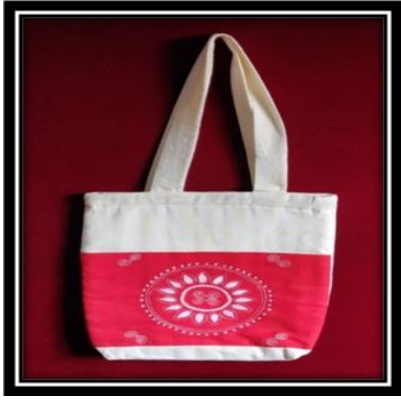

Bag 3

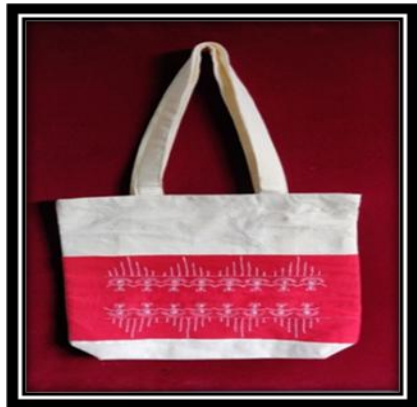

Bag 4

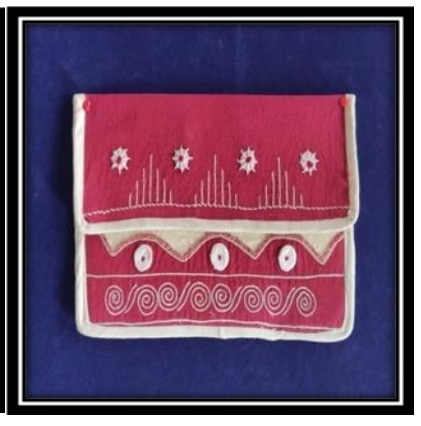

Clutch
Although same colour scheme i.e. red and white was followed for all the products. But there was difference in the respondent's opinion. Respondents have rated the product colour combination as per the suitability of scheme to the products and motifs. Bag 1 was rated highest (4.78). Rank II was given to the cushion cover 1 with $4.76 \mathrm{WMS}$, followed by cushion cover 2 with 4.72 WMS. Stole 1 and shrug was not much preferred by the respondents for colour cover combination. Respondent fount them dull and ranked XII and XIII respectively. Calculated WMS was 3.20 and 3.10 respectively.

Quality of printing was adjuged best for bag 2, a sublimation printed bag. Bag 2 had 4.94 WMS and ranked I. Ranked II was given to embroidered clutch, 4.80 was the calculated WMS. Cushion cover 2 and cushion cover 1 had 4.70 WMS and 4.64 WMS and ranked III and IV respectively. Stole 1 with 2.58 WMS was rated lowest for quality of printing. Shrug was not also appreciated by the respondents on printing quality it was ranked XII with 3.44 WMS. Cushion cover 1, bag 1 and bag 3 was highly preferred (4.92 WMS) for overall appearance, followed by cushion 2 with 4.76 WMS and bag 4 with 4.46 WMS. It was evident from the Table 1 that rank IV was given to stole 2 and cushion cover 4 got fifth rank with WMS of 4.38 and 4.30 respectively. Shrug and stole 1 has XI rank with lowest WMS of 3.70 .

Figure 1 shows the overall WMS of Aipan based developed products. It is clear from the Figure 1 Cushion cover 2 was preferred more as compared to other products. Stole 2 got minimum overall WMS, which indicated its least preference among respondents.

\section{Evaluation of the cost}

It is clear from the Table 2 that $84 \%$ of the respondent considered that the cost for the 
cushion covers is in medium range while the $12 \%$ respondent considered the cost of cushion cover per piece is low. Only $4 \%$ respondent considered that the price of cushion cover was in high range.

According to the $92 \%$ respondents, the cost of Bag 1 was in medium range while $8 \%$ respondent considered the cost of Bag 1 low. It is also clear from the Table 2 that the $76 \%$ respondent considered the cost of Bag 2 was high while $24 \%$ respondent considered the price of Bag 2 was in medium range. The high cost of Bag 2 was due to the high development cost of heat transfer printing paper. In case of Bag 3 majority of respondents i.e $70 \%$ considered that the cost of Bag 3 was in medium range while $24 \%$ considered the cost of Bag 3 was high. Very few respondents $(6 \%)$ considered the cost of bag 3 high.

In case of Bag $458 \%$ of the respondent considered that the cost for the bag 4 is in medium range while the $36 \%$ respondent considered the cost of Bag 4 was in medium range.

For stole 1, $72 \%$ respondents considered the price of stole was in medium range while $28 \%$ considered it in high range

For stole 2, 62\% respondents considered that the price of stole was in medium range while $38 \%$ considered that the price was in high range.

For clutch, $82 \%$ respondent considered the cost of clutch was in medium range, while 12 $\%$ considered the cost of product was in low range.

In case of shrug it was considered by majority of respondents (92\%) that the cost of shrug was in high range while only $8 \%$ respondent considered that the cost of shrug was in low range. The high cost range of shrug is due to the production cost of heat transfer paper. On commercial level the cost could be reduced. The fabric used for shrug was also costly for single purchase.

In conclusion, thus, in the textile sector the adapted design can be used for value addition of diversified product range. This will not only help in the preservation of Aipan but also broaden the design base for the textiles products. Migrants of Uttarakhand can also utilize their skills in experimenting with folk motifs and design to make them suitable for textile in innovative ways. This type of work will also motivate people to come up with an ingenious work, which indirectly help in upgrading the art and craft of Uttarakhand and thus India's.

\section{References}

Anynomous, 2016. A hidden art : Aipan.

Arya, A, Gahlot, M. and Rani, A. (2017). Adaptation of Aipan designs (A floor art of Uttarakhand) for designing of saree International Journal of Applied Research. 3(7): 737-743

Baral, B. Aipan Uttarakhand: Ritual Floor Painting.

Bhandari, A. 2006.The shape of my Hindu Heritage. Retrieved on March 12, 2013 from http://www.beliefnet.com

https://niharikau123.wordpress.com/2016/07/29 /a-hidden-art-Aipan/ on February 2020.

Traditional Aipan Retrieved from http://www.99uttarakhand.in/traditional -Aipan.php on April 2019.

Upadhayay, H. (2013). adaptation of traditional Aipan designs on apparels through block printing with natural thickening agent. M.sc. Thesis department of textiles and apparel designing college of home science, Udaipur Maharana Pratap University of agriculture and technology, udaipur (rajasthan). 
How to cite this article:

Manisha Gahlot, Pooja Bhatt, Deepti Pargai and Beenu Singh. 2020. Traditional Aipan Art of Kumoun - A Sustainable Development Tool. Int.J.Curr.Microbiol.App.Sci. 9(10): 3890-3898. doi: https://doi.org/10.20546/ijcmas.2020.910.448 